\title{
Diagnóstico y análisis de estructuras de madera mediante técnicas no destructivas: aplicación a la Plaza Mayor de Chinchón (Madrid)
}

\author{
Diagnosis and assessment of timber structures using non- \\ destructive techniques: application to the Plaza Mayor in \\ Chinchón (Madrid)
}

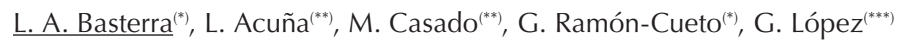

RESUMEN

Este artículo muestra los trabajos de inspección, diagnóstico y propuesta de intervención sobre la estructura de madera vista de la plaza Mayor de Chinchón (Madrid). Se emplearon técnicas de reconocimiento visual y otras de tipo no destructivo y pseudo-no destructivo como la microfotografía, xilohigrometría, medición de la velocidad de ultrasonidos, arranque de tornillos y resistografía. Los trabajos permitieron identificar la especie leñosa original, caracterizar la madera estructural, señalar los daños y lesiones de diverso tipo que presenta $y$, finalmente, realizar una peritación estructural. Todo ello sirvió de base para establecer una propuesta de intervención basada en los datos obtenidos y los principios generales internacionalmente reconocidos, aplicados al caso particular. Aunque el estado general de la madera es relativamente bueno gracias a actuaciones realizadas anteriormente, se propusieron sugerencias de intervención constructiva y tratamientos contra daños bióticos y abióticos. Ha sido realizado por el Grupo de Investigación en Estructuras y Tecnología de la Madera de la Universidad de Valladolid (http://www.uva.es/maderas), que está integrado por profesionales e investigadores multidisciplinares, con experiencia en los campos de la construcción y restauración arquitectónica y la tecnología de la madera.

464-7

Palabras clave: diagnóstico estructural, ensayos no destructivos, estructuras de madera, patrimonio cultural, Chinchón.

\section{SUMMARY}

This article shows the work attributed to the assessment, diagnosis and intervention proposal regarding the seen timber structure at the Plaza Mayor in Chinchón (Madrid). Visual recognition techniques and other non-destructive and pseudo non-destructive methods were used such as microphotography, xilohigrometry, ultrasound velocity measurements, screw extraction and resistography.The investigative work allowed for the identification of the original woody species, the characterization of the structural timber and the identification of diverse types of damages and lesions present in order to carry out a structural assessment. It served as a basis to establish an intervention proposal based on the obtained data and the internationally recognized general principles applied to the particular case. Although the overall state of the timber is quite good, thanks to the actions carried out previously, suggestions for constructive intervention and treatments against biotic and abiotic damages were proposed.The investigative work was carried out by the research group of Timber Structures and Wood Technology of the University of Valladolid (http://www.uva.es/maderas), which is composed of multidisciplinary researchers with experience in the fields of construction and architectural restoration and wood technology.

Keywords: structural diagnosis, non destructive tests, timber structures, cultural heritage, Chinchón. 


\section{PlanteAmiento MetOdOlÓGico}

En este trabajo se ha empleado una sistemática original de inspección, representación y análisis para la evaluación del estado de los elementos estructurales de madera en el patrimonio construido (13). Fue desarrollada con el objetivo de facilitar a los agentes intervinientes un procedimiento de diagnóstico contrastado y fiable, orientado al establecimiento de criterios y a facilitar la toma de decisiones en los proyectos arquitectónicos de intervención sobre este tipo de estructuras. Utiliza conocimiento proveniente de la teoría y el proyecto de restauración y de la construcción arquitectónica, así como de la tecnología de la madera y la ingeniería de montes. Por ello tiene una condición eminentemente interdisciplinar.

La fase de inspección en obra se basa en una colección limitada de técnicas visuales e instrumentales de carácter no destructivo o pseudo no destructivo, portátiles y con posibilidad de uso en obra, apoyándose en el perfeccionamiento y adaptación contextual de métodos de ensayo ya experimentados internacionalmente (4)(8) a las peculiaridades de las piezas estructurales de madera más frecuentes en el patrimonio históricocultural de España, así como en trabajos previos de los autores realizados en laboratorio y en obras construidas (6)(7).

Como soporte del análisis estructural se realiza una codificación e integración de dibujos, documentos y resultados de los ensayos que se plasma en documentos hipertextuales. Éstos pueden ser analizados por técnicos ajenos al equipo de inspección, facilitando la toma de decisiones de proyecto. El sistema es compatible para su impresión en formato papel (14).

Las comprobaciones estructurales se realizaron por el método de los Estados Límite, siguiendo los procedimientos establecidos por el Eurocódigo 5 (1), puesto que en la fecha de su realización aún no estaba publicado el documento básico del Código Técnico de la Edificación correspondiente: DB SE-Madera.

\section{LA PLAZA MAYOR DE CHINCHÓN}

El conjunto de edificaciones alrededor de la plaza Mayor de Chinchón configuran un espacio urbano de gran interés arquitectónico e histórico que obedece, entre otras, a dos razones fundamentales: su particular configuración espacial y constructiva, asociada a un uso que fue en su día común en muchas localidades castellanas, y al hecho de estar edificada con un material como la madera, que ha tenido no pocas dificultades para sobrellevar el paso del tiempo en estos tipos constructivos tan expuestos (Fig. 1). Ello se ha debido no tanto a la falta de prestaciones constructivas o a deterioros inevitables, sino al hecho de haber sido asociada durante mucho tiempo a una imagen de obsolescencia y falta de modernidad que llevó al derribo y la sustitución de tantas estructuras históricas. Afortunadamente tan lamentable situación está siendo progresivamente relevada por un sentimiento general de aprecio y valoración del patrimonio histórico como bien cultural desde hace bien pocos años.

La plaza se levanta en el centro geométrico del casco histórico (Fig. 2), entre el primiti-

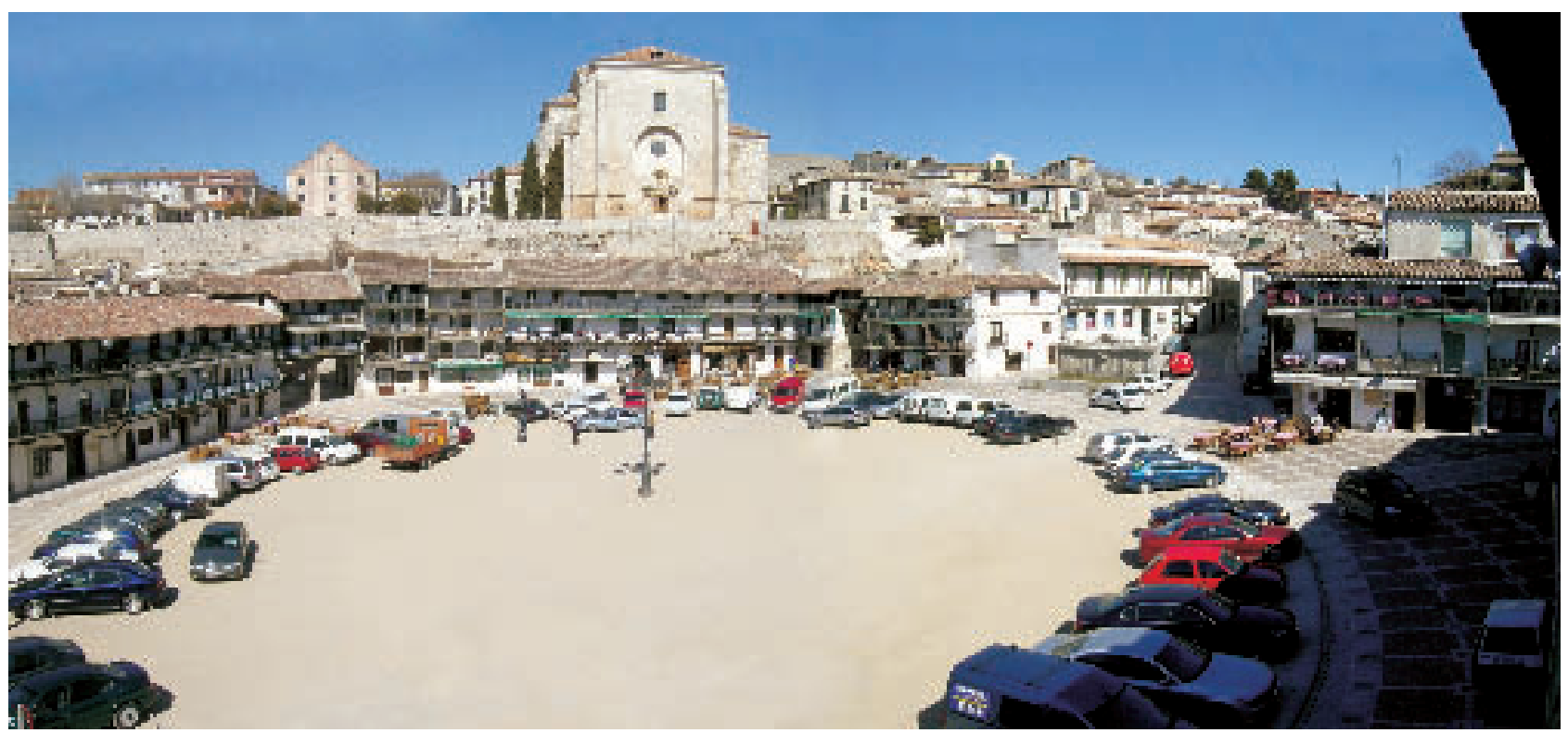




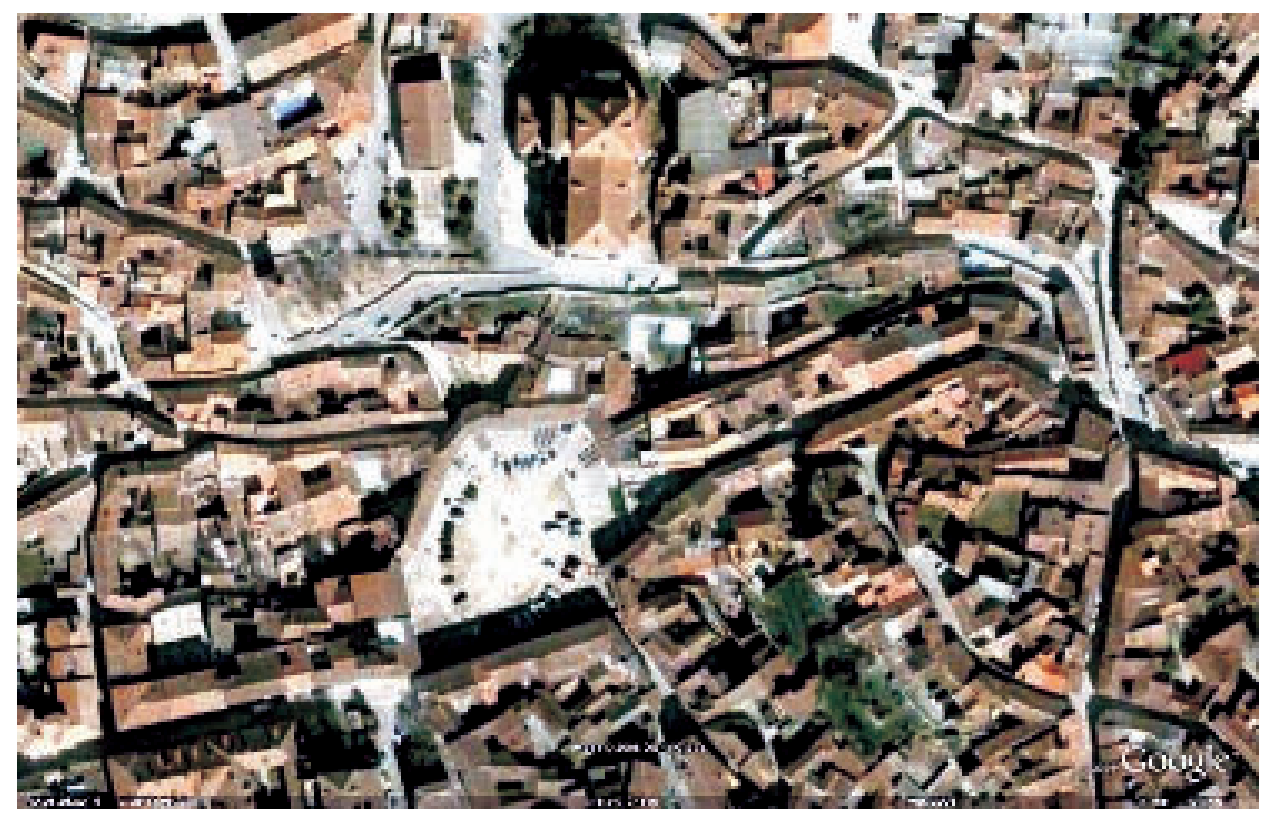

2. Situación dentro del núcleo urbano (foto: Google Earth, 2006).

3. Esquema de la división en unidades.

vo núcleo urbano del barrio de San Antón y el Castillejo, en la cabecera de un valle excavado por los arroyos que bajaban por las calles de las Mulillas y Grande o de José Antonio, a los que se unía la torrentera de la calle del Barranco. Su importancia hizo que ya fuese incluida, en el siglo XVII, por el conde de las Navas entre las "reales plazas" de España, estando hoy declarada Bien de Interés Cultural y contando con el grado de protección más elevado -Grado $1{ }^{\circ}$ Protección integral- en su planeamiento urbanístico.

Su riqueza espacial la proporcionan tanto la escala como la complejidad y variedad de perspectivas disponibles, derivadas de una planta y una topografía escasamente regular que se ha ido solventando en el tiempo de forma tan descoordinada como de resultado coherente. El desnivel del terreno en dirección oeste-este se ha resuelto mediante diferentes alturas del caserío y los tramos edificados son interrumpidos, a intervalos desiguales, por las cinco calles que se abren a la plaza. Además de pocas, estas salidas han sido sucesivamente estrechadas Ilegándose incluso a construir pasos elevados sobre las calles.

La plaza cuenta con 234 balcones o "claros" sobre los que aún se mantiene la tradición de la "requisa" o derecho a disfrutar de las balconadas durante las fiestas taurinas, que está disociado de la propiedad de la vivienda por las que tienen acceso, cargando sobre estas últimas una servidumbre de paso para los propietarios de aquéllas. Para su estudio, en este trabajo, la plaza se ha dividido en seis tramos o unidades, aprovechando esta estructura de calles que llegan a ella (Fig. 3).

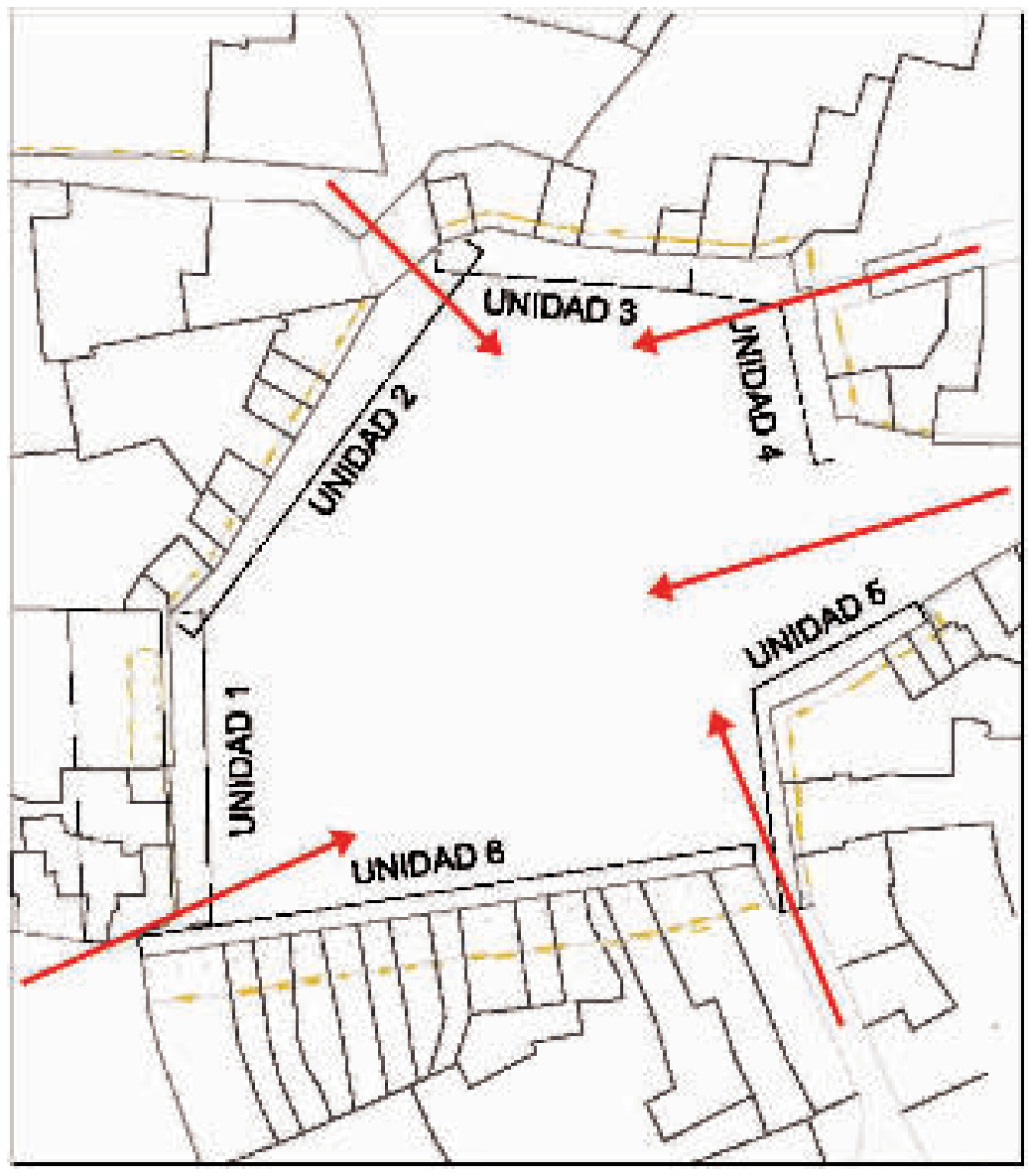

Se parte de la calle de los Huertos, siguiendo el sentido de las agujas del reloj para recorrer todo el perímetro.

Mediante el estudio histórico realizado se han documentado intervenciones relevantes posteriores a la construcción original, 
4. Fotografía del lado del Ayuntamiento, hacia $1959^{1}$

5. Arquillos superpuestos en algunas balconadas, hacia $1970^{2}$.

6. Serie de secciones tipo. por ejemplo en el edificio del Ayuntamiento (Fig. 4), prácticamente reconstruido, así como otra serie de ellas, de menor influencia en la configuración original (Fig. 5). Una alteración superficial pero importante fue la que supuso, en 1958, suprimir el color azulete o añil de las carpinterías originales, un tono tradicional de la Mancha -resultado de aplicar una imprimación repelente de los insectos xilófagos obtenido al mezclar carbonato de plomo y aceite de linaza con blanco albayalde y azul índigo- y pintar de verde todos los balcones de la plaza para unificar su color. Otras intervenciones relevantes más recientes fueron proyectadas y dirigidas por el arquitecto Salvador Pérez Arroyo, por encargo de la Dirección General de Patrimonio Cultural de la Comunidad de Madrid, en 1992.

\subsection{Modelo estructural y constructivo}

Los elementos estructurales de madera vista de la plaza Mayor de Chinchón presentan un patrón común que puede describirse a partir de su sección tipo (Fig. 6). En el nivel superior o de cubierta, los parecillos inclinados emergen a través de los muros hasta alcanzar una jácena frontal en el plano de las balconadas. Por su continuidad con el vano interior, el tramo exterior responde a un modelo empotrado-apoyado, y las jácenas actúan como tal, entregando la carga, a través de unas generosas zapatas, a los correspondientes pies derechos.

Éstos a su vez descansan en su base sobre un durmiente que reparte la carga vertical en los extremos de una nueva familia de viguetas, en el nivel inferior. A partir de aquí, en los niveles intermedios, se produce una contradicción entre la apariencia porticada de los frentes de las balconadas (Fig. 7) y su verdadero trabajo estructural. Puede observarse que los extremos de las viguetas no se apoyan en una jácena frontal como en el caso de la cubierta (Fig. 8) sino que, dada su continuidad con el tramo interior, trabajan como ménsulas empotradas en los muros de cerramiento dorsales, y son in-
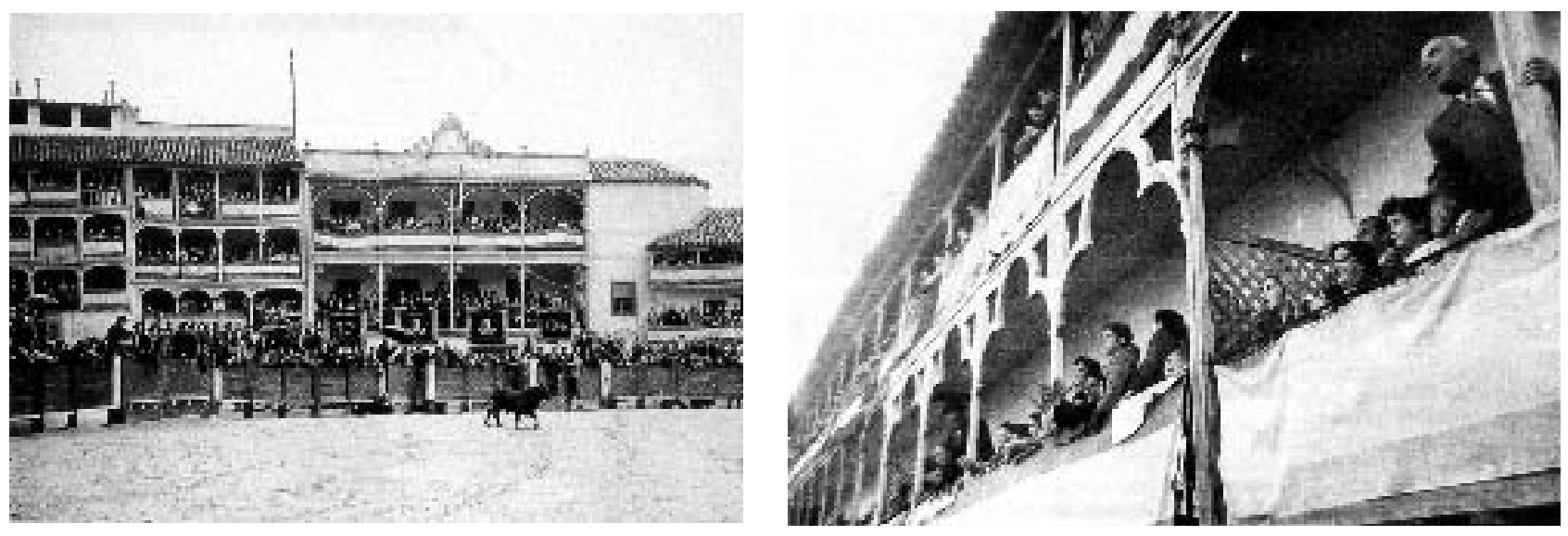

Obsérvese la configuración de la fachada del Ayuntamiento y la ya evidente deformación de las casas núms. 1 y 2 . A.G.A. Patronato de Turismo. Fotografía publicada en AA.VV.: Colección Arquitectura y Desarrollo Urbano; Comunidad de Madrid, Tomo XI, Consejería de Medio Ambiente y Ordenación del Territorio, Dirección General de Arquitectura y Vivienda; Fundación Caja Madrid y Fundación COAM, 2004.

${ }^{2}$ ARCAM Archivo fotográfico Martín Santos Yubero. Fotografía publicada en AA.VV.: Colección Arquitectura y Desarrollo Urba-
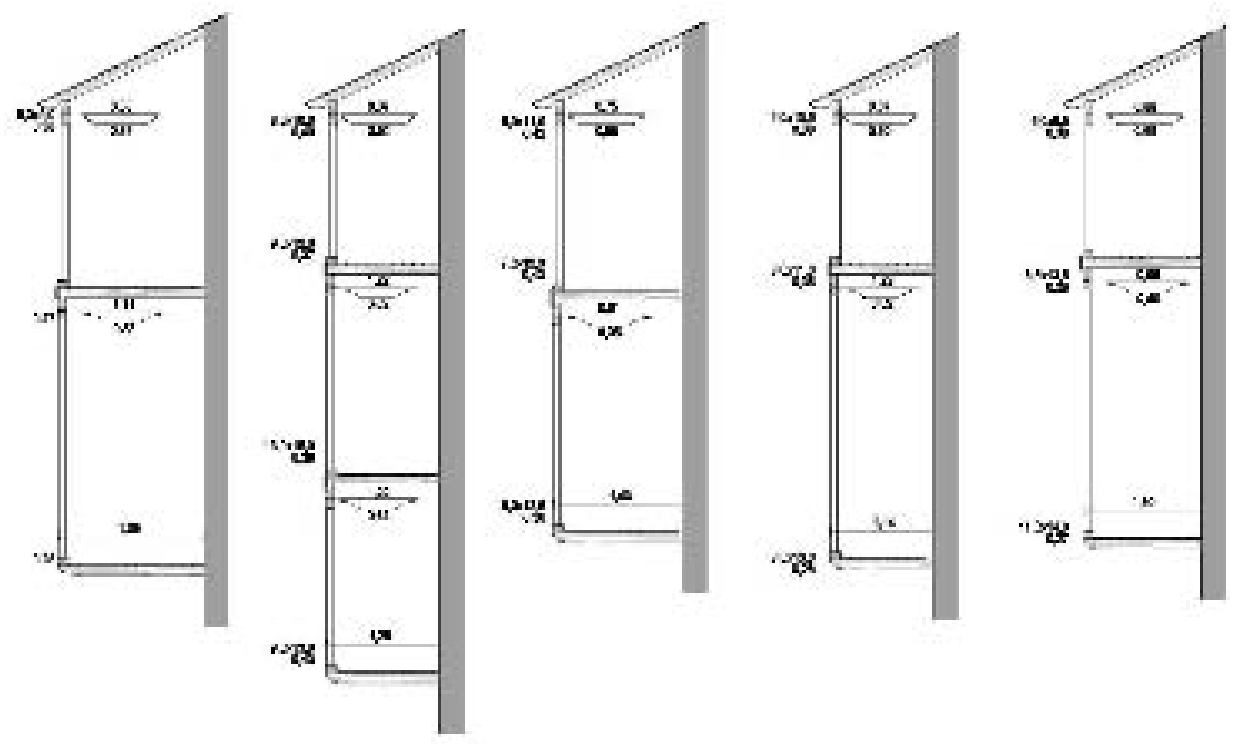
no; lb.

I.r.os.r.

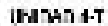

Fanan :-T 


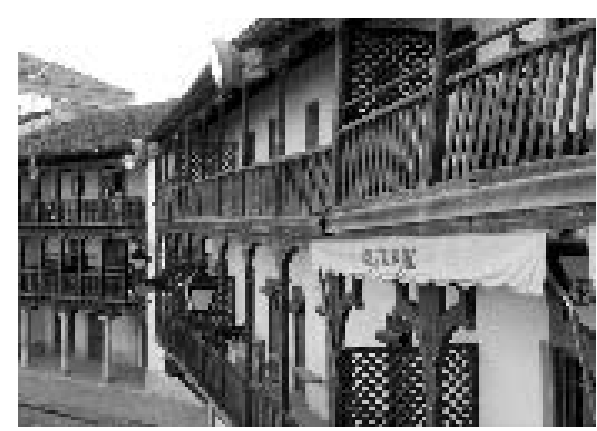

dependientes del pórtico frontal, que sólo sirve para la sujeción de barandillas y antepechos. Estos se van sujetando entre los pies derechos, cuya escasa escuadría ya denota su exigua capacidad estructural, y la posibilidad de vuelco hacia delante de todo el conjunto se confía a las subdivisiones de propiedades y precarios medios mecánicos de tipo clavija.

Las casas núms. 1 y 2, entre la calle de los Huertos y el Ayuntamiento, constituyen dos excepciones a este esquema general pues la mayor profundidad de sus galerías, algo superior a los tres metros, impide la configuración de ménsula volada, respondiendo a un modelo empotrado-apoyado, análogo al del nivel de cubierta.

La descripción de este modelo constructivo, distinto del aparente, resultará de utilidad para la peritación estructural a realizar, una vez caracterizada la madera y localizados los daños y lesiones que presenta, según se describirá más adelante.

\section{MATERIAL Y MÉTODOS}

\subsection{Inspección visual, documentación fotográfica y examen superficial}

Incluso antes de la publicación del CTE, en España estaba ya normalizado, a través de la norma UNE-EN 338:2003, el sistema de clases resistentes. Se basa en clasificar la madera por clases, cada una de las cuales tiene fijadas sus propiedades elásticas y resistentes. Para conocer a qué clase resistente pertenece un espécimen o una población de madera se debe tener en cuenta la especie de que se trate y su calidad, entendiéndose ésta como la mayor o menor presencia de las singularidades que experimentalmente se ha comprobado que perjudican el comportamiento estructural del material lígneo. Las diversas normas nacionales han establecido en cada país la forma de medir tales singularidades, y los límites que se admiten en cada calidad, realizándose este proceso de forma visual. La norma española de referencia para coníferas es la UNE 56.544 "Clasificación visual de la madera

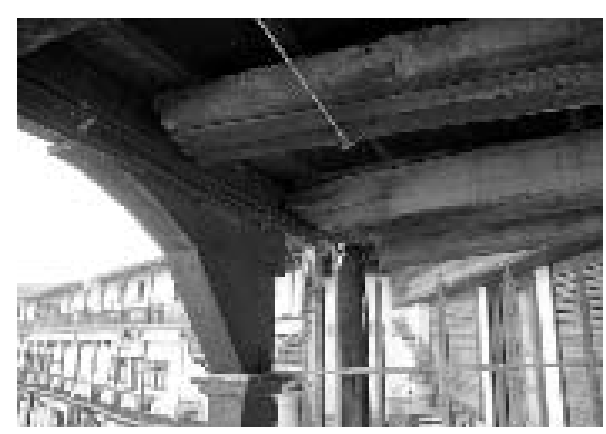

aserrada de uso estructural. Madera de coníferas". Trabajos publicados en los últimos años (5) (6) han llamado la atención sobre la escasa aptitud de estas normas, y en concreto la española UNE 56.544, para clasificar madera de escuadrías medianas y grandes, pues fueron diseñadas y experimentadas para secciones menores, más frecuentes en el ámbito comercial. Como consecuencia se producen porcentajes de rechazo injustificados, a la vista de los resultados obtenidos en máquina de ensayos hasta la rotura. Recientemente, autores como Arriaga (5) y Conde (9) han podido demostrar que en madera de gran escuadría las singularidades más influyentes en el comportamiento estructural son los nudos y la desviación de la fibra, y han propuesto la asignación a este tipo de elementos estructurales valores mecánicos que no tienen por qué pertenecer a una misma clase resistente.

La inspección visual permite la obtención de datos iniciales sobre las lesiones de tipo biótico y abiótico que puede presentar la estructura y proponer las zonas en las que se realizarán ensayos de los que se recogen en los párrafos que siguen. En este trabajo se seleccionaron piezas de las seis zonas en las que se dividió la plaza para su estudio, con un número equilibrado para cada una de ellas, y escogiendo las que presentaban mejores condiciones para la realización del ensayo concreto a realizar sobre ellas.

El resultado de esta inspección se refleja en planos mediante una serie original de iconos y códigos de colores que nuestro grupo de investigación ha desarrollado con vocación pre-normativa (14). Mediante ellos se llega a tres series complementarias de planos, a saber:

A. Singularidades de la madera. Se recogen todas aquellas singularidades de la madera que por ser inherentes a su propia naturaleza material no pueden calificarse como defectos o lesiones, pero redundan en una merma de sus prestaciones resistentes.

B. Patologías. Recogen los daños y degradaciones que pueden considerarse específicos de la madera como material estructural.
7. Apariencia porticada de la estructura de las balconadas.

8. Falta de apoyo de los extremos de las ménsulas sobre la falsa jácena. 
9. Xilohigrómetro.

10. Lectura en obra.
C. Lesiones constructivas. En esta última serie se han recogido el resto de defectos y lesiones, no específicos de las estructuras de madera.

\subsection{Microfotografía}

La identificación de la especie de madera es esencial pues sirve, entre otras cosas, para tener una aproximación general a las características físico-mecánicas, de resistencia natural a los ataques bióticos habituales y de impregnabilidad para la posible aplicación de tratamientos curativos o protectores. También para la asignación final de su clase resistente.

Para tener una primera aproximación de la especie de que se trata se realiza una identificación macroscópica en distintas zonas de la estructura, pero para tener una certeza positiva en la identificación de la especie se debe proceder a su análisis microscópico. Para realizarlo se preparan cubos de $15 \times 15 \mathrm{~mm}$ de lado a los que se realizan cortes en cado uno de los tres planos (longitudinal, radial y tangencial) con un microtomo, obteniendo láminas de un grosor entre 25 y $50 \mu \mathrm{m}$. El microtomo empleado en el presente estudio es un SM $200 \mathrm{R}$ de la marca LEICA.

Tras un proceso de tinción con safranina y lavado, las láminas se montaron sobre un portaobjetos para ser observadas al microscopio de transmisión, procediendo a su identificación con la ayuda de las correspondientes claves. El microscopio utilizado en este caso es un modelo DMLB de la marca LEICA.

Fueron identificadas 19 muestras extraídas de diferentes pilares, vigas y viguetas.

\subsection{Xilohigrómetro}

La humedad y la densidad son las primeras propiedades que se relacionaron con las características mecánicas, y hoy es sobradamente conocido que cuando aumen-

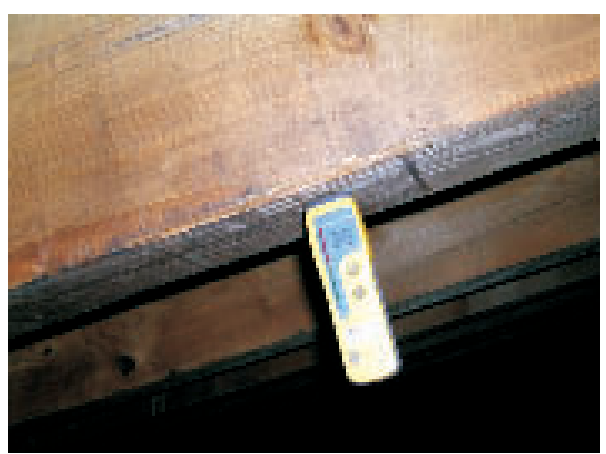

ta el contenido de humedad en la madera disminuyen su resistencia y su módulo de elasticidad. El xilohigrómetro puede medir la conductividad eléctrica entre dos electrodos en forma de púas de acero que se clavan en la madera (Figs. 9 y 10). Ofrece una medida de la humedad superficial de la pieza, en el punto concreto en el que es clavado, basándose en la relación que existe entre el contenido de humedad y la resistencia óhmica.

En este estudio se tomaron datos de la humedad de los elementos estructurales con un xilohigrómetro de resistencia, modelo Surveymaster, en 3 zonas distintas de cada una de las piezas que fueron ensayadas con el resto de equipos, resultando un total de 171 determinaciones.

\subsection{Velocidad de propagación de ultrasonidos}

La medición de la velocidad de propagación de ultrasonidos a través de la madera es una técnica no destructiva bastante desarrollada y sobre la que existen abundantes estudios (2)(9). Se basa en que la presencia de oquedades, nudos, bolsas de resina o degradaciones internas, hacen que la velocidad de transmisión de las ondas ultrasónicas que viajan a través del material leñoso sea diferente de la que se presenta en ausencia de defectos. La aplicación de esta técnica tiene la ventaja de poder ser empleada in situ para la evaluación de madera puesta en obra.

El equipo empleado en este trabajo es un modelo Sylvatest ${ }^{R}$ que utiliza una frecuencia de $30 \mathrm{kHz}$ y mide el tiempo (ms) que tarda la onda ultrasónica en llegar de un palpador emisor a otro receptor. Conociendo la longitud de la pieza y la densidad del material se puede determinar el Módulo de Elasticidad Dinámico a partir de la ecuación:

Módulo de Elasticidad Dinámico $=$ Densidad $\times$ Velocidad ${ }^{2}$

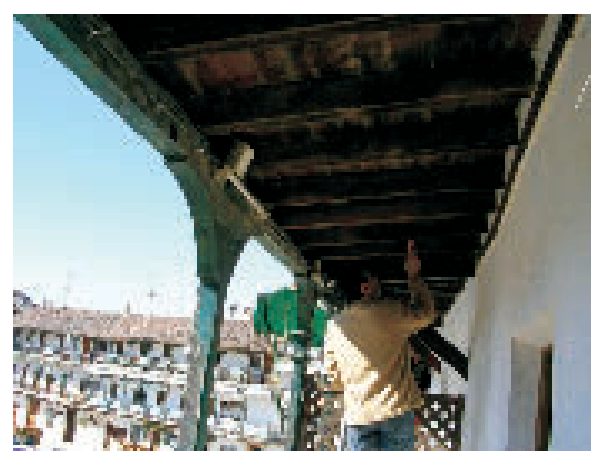


Esta relación entre la velocidad de la onda y el módulo de elasticidad aporta información sobre la calidad general de la piezas, sin embargo su relación con la resistencia última no es tan clara ya que ésta suele depender de algún defecto local que produce la rotura y en la velocidad de propagación de la onda ese defecto, en concreto, puede tener poca influencia.

Con esta técnica la medición puede hacerse de forma directa, tomada con los palpadores colocados de testa a testa, en paralelo con el eje de la pieza (Fig. 11); o indirecta, con los palpadores colocados en la misma superficie u opuesta, formando un ángulo con la superficie de la pieza y de manera que la onda ultrasónica no recorre la pieza de forma longitudinal (Fig. 12).

La medición directa es más fiable y apropiada como variable predictora, pero en las piezas puestas en obra normalmente no son accesibles las testas de las piezas, y debe realizase la medición indirecta. Para poner en relación ambos valores nuestro grupo de investigación, trabajando con el equipo Sylvatest, ha publicado (2) unas funciones correctoras dependientes de la especie y del ángulo que forman la dirección longitudinal y la línea de unión de los palpadores, y permiten relacionar numéricamente las mediciones indirectas con las directas.

En este estudio se realizaron medidas indirectas de 14 pilares, 26 viguetas y 17 vigas, situando los palpadores con un ángulo de $45^{\circ}$ entre el eje longitudinal de la pieza y la superficie de las caras. Posteriormente las mediciones de velocidad fueron corregidas en función de la distancia de colocación de los palpadores y del ángulo formado por la línea que los unía y la directriz de la pieza, de forma que fueran asimilables a mediciones directas.

\subsection{Extracción de tornillos}

Esta técnica de ensayo es un método pseudo-no destructivo que utiliza un dispositivo que registra la máxima fuerza que se precisa para arrancar un tornillo de características específicas previamente introducido en la pieza de madera (Figs. 13 y 14).

Trabajos previos del grupo de investigación autor de este trabajo (7) hallaron una relación estadísticamente significativa entre la densidad media de la madera de Pinus y la fuerza media al arranque en el canto, con un coeficiente de determinación $r^{2}$ de 0,65.

A continuación se refleja la ecuación del modelo ajustado, en función de la citada fuerza media al arranque en el canto registrada:

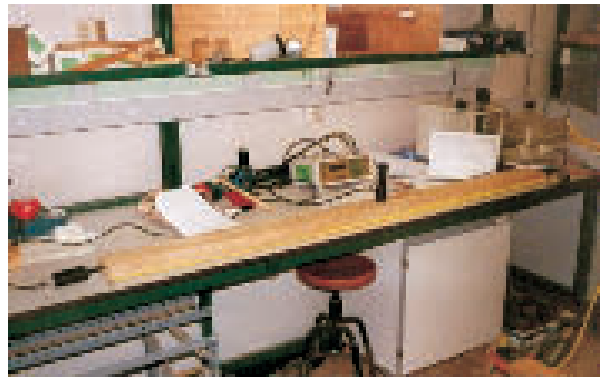

11

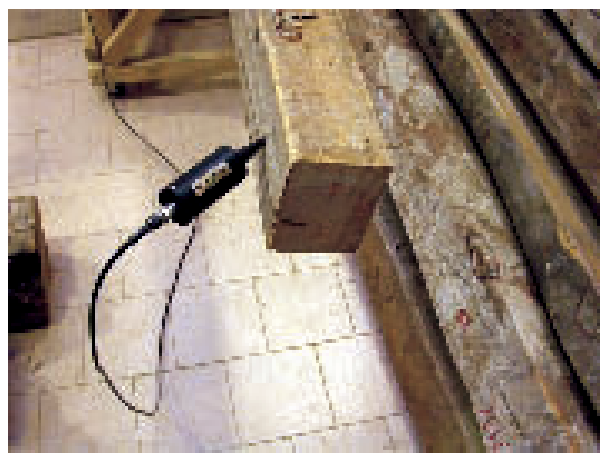

12

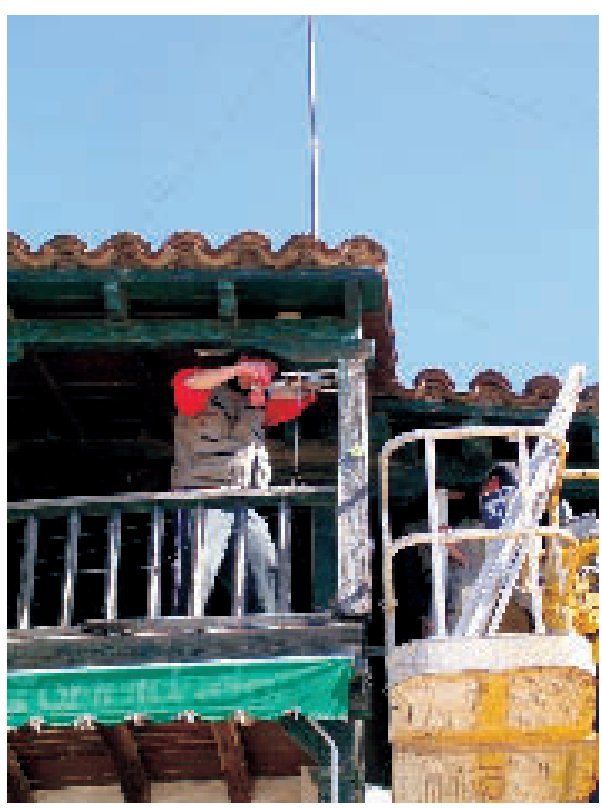

13

$\operatorname{Densidad}\left(\mathrm{g} / \mathrm{cm}^{3}\right)=\frac{1}{0,93+\frac{2,47}{\text { Fuerza canto }(\mathrm{kN})}}$

La técnica es válida también para detectar daños y lesiones ocultos en las piezas de madera, aunque en este trabajo se orientó a la obtención de la densidad, por ser un dato necesario para el ensayo con ultrasonidos.

Se empleó un aparato fabricado por Fakopp Enterprise Bt., y con él se realizaron 83 determinaciones de la fuerza de arranque de tornillo. Los tornillos utilizados eran de 4 $\mathrm{mm}$ de diámetro y $18 \mathrm{~mm}$ de longitud activa (Fig. 14), por ser los más apropiados al tipo

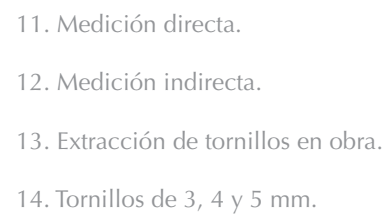

14. Tornillos de 3,4 y $5 \mathrm{~mm}$.

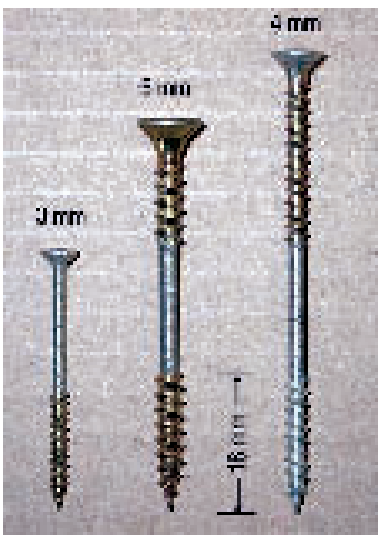

14 


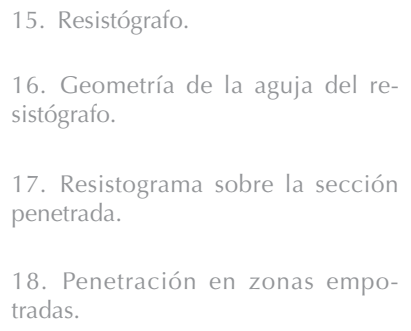

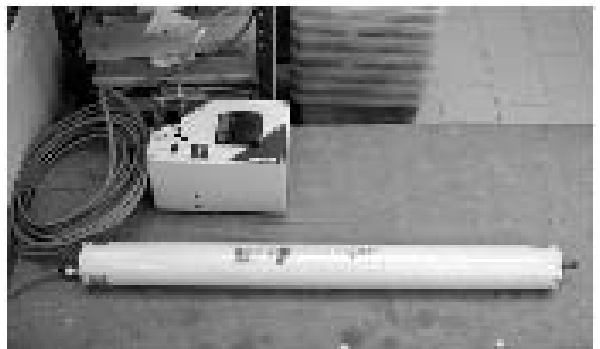

15

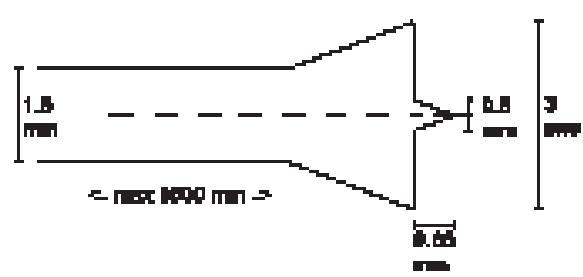

16

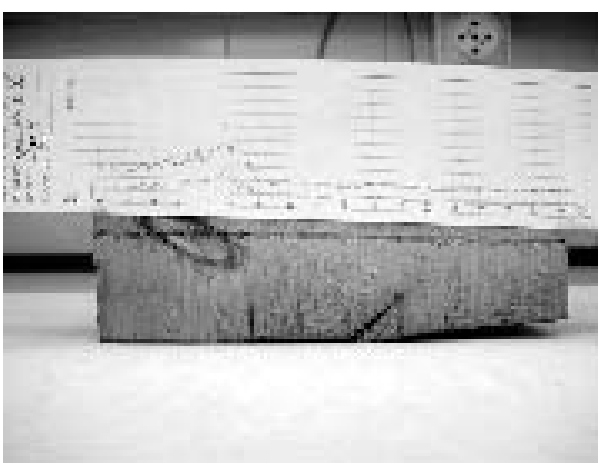

17

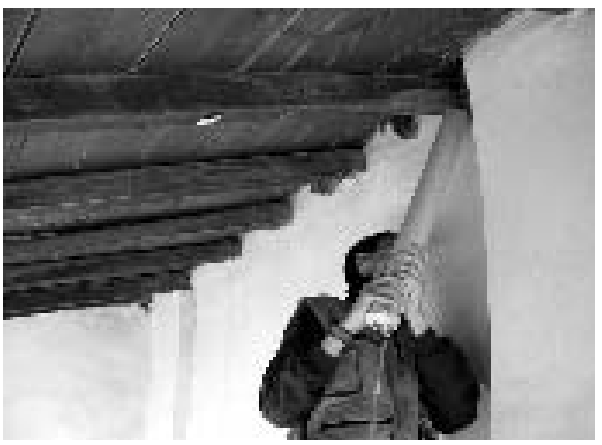

18

de madera en estudio según trabajos anteriores de puesta a punto de esta técnica ya publicados por los autores (7).

\subsection{Resistógrafo}

La resistografía se basa en la evaluación de la energía consumida al penetrar la madera con una aguja calibrada, es decir, la resistencia que la madera opone a la penetración de una broca a velocidad constante, medida como el consumo de potencia del motor del taladro, que podrá relacionarse con la densidad (13)(15). En concreto se mide la resisten- cia a la penetración de una broca de $1,5 \mathrm{~mm}$ de diámetro de vástago y $3 \mathrm{~mm}$ en la cabeza (Fig. 16). La potencia consumida es variable según la zona que atraviese y son esas variaciones las que ofrece el aparato gráficamente en forma de resistograma (Fig. 17). La integral de la curva potencia consumida-tiempo es la variable esencial indicadora del ensayo. La resolución del método es tan alta, que se pueden detectar variaciones de densidad incluso entre los anillos de crecimiento.

Para el desarrollo del presente estudio, se ha utilizado un resistógrafo RINNTECH,

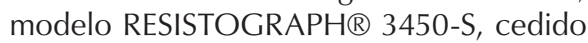
por la empresa TRYCSA a la Universidad de Valladolid. Externamente el equipo consta de dos partes: el sistema de accionamiento mecánico con la aguja perforadora y el dispositivo de recogida y almacenamiento de datos que incluye una batería recargable (Fig. 15). La geometría de la punta de la aguja tiene dos veces el espesor del vástago debido a que la fuerza ejercida se concentra en dicho punto. En total se han realizado 216 ensayos de penetración con el resistógrafo, en 93 elementos (20 pilares, 23 vigas y 50 viguetas). Una vez realizados los análisis de identificación de la especie de madera y habiendo comprobado que se trata en todos los casos de la misma especie, se realiza un análisis estadístico de los datos resistográficos que permitirá su diagnóstico y determinar otros parámetros del elemento resistente.

El registro de datos se realiza durante la realización del ensayo de forma instantánea y de dos formas:

- Gráficamente a escala 1:1, con una resolución de 0,1 mm e impresión en papel térmico (Fig. 17).

- Numéricamente, se almacenan directamente en el ordenador 1.000 datos por cada centímetro de penetración de la aguja.

Una de las posibilidades más interesantes que ofrece este dispositivo es la inspección de la zona oculta de las cabezas de las piezas que entran dentro de los muros, posibilitando la detección de pudriciones interiores en zonas especialmente sensibles a la degradación y susceptibles de acarrear problemas graves en el futuro (Fig. 18).

\section{DISCUSIÓN DE RESULTADOS}

\subsection{Microfotografía}

Se identificaron 19 muestras de madera, todas ellas como pertenecientes al género Pinus del grupo Pinoide 1, con punteaduras tipo ventana que corresponden a las espe- 

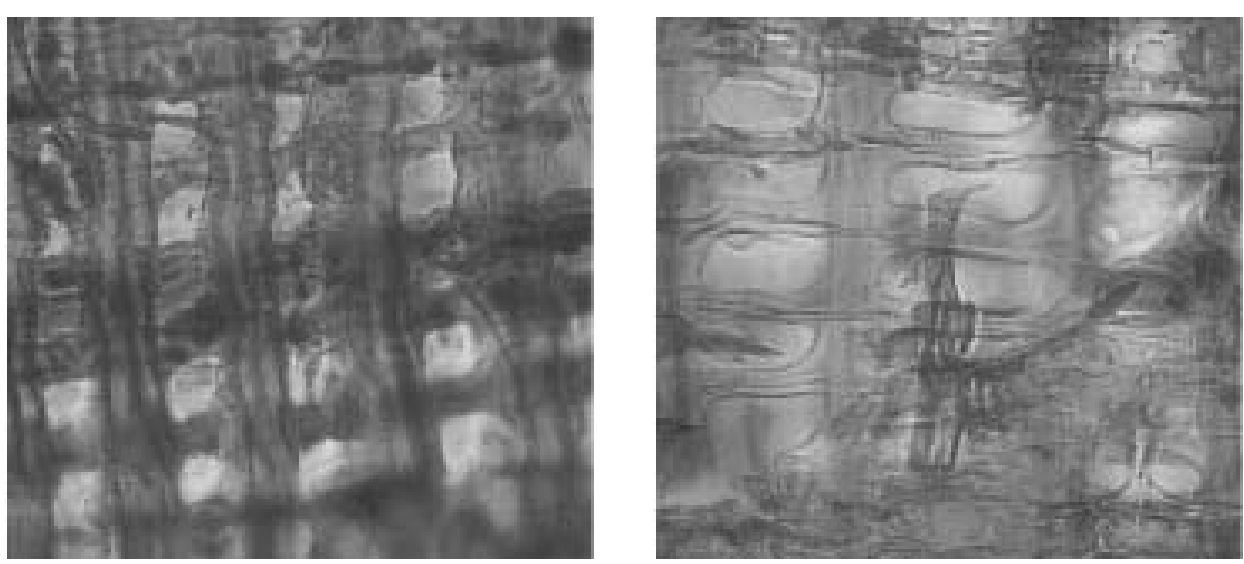

20

cies: Pinus silvestre, Pinus uncinata o Pinus nigra (Figs. 19 y 20). Dadas las características anatómicas y morfológicas de este grupo de especies, no es posible una mayor precisión en la identificación microscópica de manera que, teniendo en cuenta la tradición local y la información recabada en rehabilitaciones anteriores, inicialmente se estimó que la madera utilizada en la plaza Mayor de Chinchón era de pino laricio (Pinus nigra Arn.)

Con posterioridad se pudo fijar definitivamente la especie como pino silvestre (Pinus sylvestris L.) mediante el análisis numérico de los resultados de los ensayos resistográficos, siguiendo una metodología original que nuestro grupo ha desarrollado y publicado recientemente (3).

\subsection{Determinación de la humedad con xilohigrómetro}

El contenido de humedad de la madera mediante xilohigrómetro, cuyas determinaciones se resumen en la Tabla I, ofrece unos valores medios normales para madera al exterior bajo cubierta: entre el 12,2-13,3\%, excepto en zonas puntuales en las que se ha registrado un alto contenido de humedad 17$18 \%$, afectados por salpicadura y goteras, $y$ preferentemente en la Unidad 6, orientada al norte.

\subsection{Velocidad de propagación de ultrasonidos}

Los resultados medios obtenidos de la velocidad de propagación de la onda y el Módulo de Elasticidad Dinámico deducidos de ellos aparecen en la Tabla II

Las velocidades reflejadas en la Tabla II ya han sido corregidas, en función de la distancia y el ángulo, según se expuso más arriba.

La velocidad media de propagación de la onda es ligeramente superior a $5.000 \mathrm{~m} / \mathrm{s}$, y está por encima de los datos comparables publicados por otros autores (10) (11) para la misma especie, lo que indica una buena selección original de las piezas. El Módulo de Elasticidad Dinámico calculado con la fórmula [1] a partir de la velocidad de propagación de la onda y la densidad estimada ofrece unos valores entre 10.886 y 14.048 $\mathrm{N} / \mathrm{mm}^{2}$.

El ensayo permitió fijar unos rangos de clasificación para las piezas ensayadas, la dea través del ensayo de extracción de tornillos

Tabla I

Valores medios de la humedad por tipo de pieza

\begin{tabular}{|c|c|c|c|c|c|c|}
\hline VARIABLE & \multicolumn{2}{|c|}{ PILAR } & \multicolumn{2}{c|}{ VIGUETA } & \multicolumn{2}{c|}{ VIGA } \\
\cline { 2 - 7 } & $\begin{array}{c}\text { № } \\
\text { Elem. }\end{array}$ & $\begin{array}{c}\text { Media } \\
\text { (Des. St.) }\end{array}$ & $\begin{array}{c}\text { № } \\
\text { Elem. }\end{array}$ & $\begin{array}{c}\text { Media } \\
\text { (Des. St.) }\end{array}$ & $\begin{array}{c}\text { № } \\
\text { Elem. }\end{array}$ & $\begin{array}{c}\text { Media } \\
\text { (Des. St.) }\end{array}$ \\
\hline $\begin{array}{c}\text { HUMEDAD } \\
\%\end{array}$ & 14 & $\begin{array}{c}\mathbf{1 2 , 2} \% \\
(2,4)\end{array}$ & 26 & $\begin{array}{c}\mathbf{1 3 , 3 \%} \\
(1,9)\end{array}$ & 17 & $\begin{array}{c}\mathbf{1 2 , 1 \%} \\
(2,1)\end{array}$ \\
\hline
\end{tabular}

Tabla II

Resumen de resultados del ensayo de ultrasonidos

\begin{tabular}{|c|c|c|c|c|c|c|}
\hline \multirow{2}{*}{ VARIABLE } & \multicolumn{2}{|c|}{ PILAR } & \multicolumn{2}{c|}{ VIGUETA } & \multicolumn{2}{c|}{ VIGA } \\
\cline { 2 - 7 } & № & $\begin{array}{c}\text { Media } \\
\text { (Des. St.) }\end{array}$ & № & $\begin{array}{c}\text { Media } \\
\text { (Des. St.) }\end{array}$ & № & $\begin{array}{c}\text { Media } \\
\text { (Des. St.) }\end{array}$ \\
\hline $\begin{array}{c}\text { VELOCIDAD DE } \\
\text { LA ONDA m/s }\end{array}$ & 14 & $\begin{array}{c}5.080 \mathrm{~m} / \mathrm{s} \\
(381)\end{array}$ & 26 & $\begin{array}{c}5.055 \mathrm{~m} / \mathrm{s} \\
(567)\end{array}$ & 17 & $\begin{array}{c}5.050 \mathrm{~m} / \mathrm{s} \\
(704)\end{array}$ \\
\hline $\begin{array}{c}\text { MOE dinámico } \\
\text { N/mm } \mathrm{mm}^{2}\end{array}$ & 14 & $\mathbf{1 4 . 0 4 8 ~ N / m ^ { 2 }}$ & 26 & $\mathbf{1 3 . 2 2 6 ~ N / m ^ { 2 }}$ & 17 & $\begin{array}{c}\mathbf{1 0 . 8 8 6} \\
\mathrm{N} / \mathrm{mm}^{2}\end{array}$ \\
\hline
\end{tabular}


Tabla III

Estimación de clase resistente, según Esteban (10)

\begin{tabular}{|l|l|l|}
\hline PILARES, VIGAS Y & $\vee>4.900 \mathrm{M} / \mathrm{S}$ & C22 (ELS) \\
VIGUETAS & & C16 (ELU) \\
\hline
\end{tabular}

Tabla IV

Resumen de resultados del ensayo de extracción de tomillos

\begin{tabular}{|l|c|c|c|c|c|c|}
\hline \multirow{2}{*}{ VARIABLE } & \multicolumn{2}{|c|}{ PILARES } & \multicolumn{2}{c|}{ VIGUETAS } & \multicolumn{2}{c|}{ VIGAS } \\
\cline { 2 - 7 } & № & Media (Des. st) & № & Media (Des. st) & № & Media (Des. st) \\
\hline $\begin{array}{l}\text { FUERZA MÁXI- } \\
\text { MA KN }\end{array}$ & 17 & $3,07 \mathrm{KN}(0,48)$ & 44 & $2,94 \mathrm{KN}(0,53)$ & 22 & $2,99 \mathrm{KN}(0,48)$ \\
\hline $\begin{array}{l}\text { DENSIDAD } \\
\text { ESTIMADA }\end{array}$ & 17 & $557 \mathrm{~kg} / \mathrm{m}^{3}$ & 44 & $548 \mathrm{~kg} / \mathrm{m}^{3}$ & 22 & $542 \mathrm{~kg} / \mathrm{m}^{3}$ \\
\hline
\end{tabular}

tección de valores anómalos que indicaban alteraciones o degradaciones internas, y la estimación de un Módulo de Elasticidad estático ligeramente superior a $11.000 \mathrm{~N} / \mathrm{mm}^{2}$, que correspondería a una clase resistente C22. No obstante, considerando el por ahora deficiente valor predictivo de este ensayo para la resistencia última a flexión, se tuvo en cuenta la estimación propuesta por Esteban (10) que se refleja en la Tabla III

\subsection{Ensayos no destructivos mediante extracción de tornillos}

En la Tabla IV se adjuntan los valores medios de la fuerza máxima de extracción y la densidad estimada según la fórmula [2] por tipo de pieza.

Estos resultados pueden compararse con los obtenidos para madera nueva en trabajos anteriores (11), que para pino silvestre establecen valores medios de $503 \mathrm{~kg} / \mathrm{m}^{3}$ y para el pino laricio o nigra de $581 \mathrm{~kg} / \mathrm{m}^{3}$.

Los ensayos determinaron que la madera de la plaza de Chinchón tendría, en la línea de lo comentado anteriormente, una densidad intermedia entre las dos especies mencionadas.

\subsection{Resistografía}

Trabajos anteriores atestiguan que, por el momento, no puede considerarse adecuado predecir la resistencia final de toda la pieza exclusivamente a partir del ensayo del resistógrafo, aunque mediante ensayos a rotura se ha encontrado una buena relación entre aquélla y el valor medio resistográfico (13). El número de ensayos realizado (216) y su tratamiento estadístico permitió definir las variables significativas para interpretar los resultados obtenidos, de acuerdo a una metodología ya ensayada y validada con anterioridad por los autores (3). Además:

- Se aplicó con éxito un análisis discriminante con ocho variables independientes que permitió determinar, con una probabilidad del $85 \%$, que la especie leñosa empleada en la construcción de la estructura es pino silvestre. Esta conclusión se considera muy relevante, dado que los análisis microscópicos inicialmente no habían podido llegar más allá de concretar la pertenencia al género Pinus del grupo Pinoide 1.

- Se pudieron encontrar desviaciones del valor de la energía media necesaria para la penetración por su parte inferior, achacables a una pérdida de resistencia del material y no a otras circunstancias como densidad, especie, humedad, etc., que en otros casos se podrían presentar. De hecho, se determinaron los valores extremos de rango inferior y el límite de tolerancia, lo que, junto al análisis de las irregularidades gráficas, permitió establecer un criterio de clasificación orientado a la toma de decisiones de proyecto.

- Se analizaron aquellas piezas que presentaban en su secuencia resistográfica un coeficiente de variación excesivamente grande (Outlayers), indicador de importantes diferencias entre sus valores, siendo muy probable encontrar en ellas valores mínimos correspondientes a fendas, pérdidas importantes de resistencia por causas bióticas o abióticas, etc. A estos efectos fueron revisados todos y cada uno de los gráficos resistográficos determinando, en su caso, la importancia de las anomalías.

\subsection{Singularidades}

En un trabajo de este tipo, y con independencia de los valores y propiedades obtenidos con carácter general mediante los ensayos que se han descrito, resulta de vital importancia el examen pormenorizado de aquellas singularidades que pueden afectar de forma importante a la resistencia general del elemento, teniendo en cuenta la posibilidad física de evaluarlas, ya que estando la estructura en servicio, no es posible medir y/o apreciar la existencia de algunas de ellas (médula, anillos de crecimiento, madera juvenil, etc.) No obstante, las que más afectan a las prestaciones mecánicas de la madera estructural, como son la presencia de nu- 
dos y la desviación de la fibra, sí pudieron mayoritariamente ser evaluadas.

\subsection{Daños de origen biótico y abiótico}

Destaca, por estar muy extendida, la presencia de meteorización lígnea, sobre todo en las cabezas de las viguetas que soportan las balconadas. En cuanto al resto de patologías bióticas, el estado general de la madera puede considerarse como razonablemente bueno gracias a sus buenas condiciones de ventilación y a actuaciones anteriores. Algunas de ellas, sin embargo, no fueron del todo acertadas, por ejemplo la introducción de masillas en las grietas y fendas de las testas de muchas viguetas con el fin de reponer los daños causados por la meteorización y pudrición cúbica. Al tener este relleno un comportamiento higroscópico distinto al de la madera el daño ocasionado ha sido mayor que si no se hubiera puesto nada.

Se han detectado daños causados por hongos cromógenos de azulado y presencia de hongos de pudrición parda o cúbica, como patología muy extendida pero de alcance limitado en sección. Se han diagnosticado daños de diversa gravedad causados por insectos xilófagos en concreto de dos familias de insectos de ciclo larvario: Anobiidae (comúnmente llamados carcoma) y Cerambycidae (conocidos como carcoma gruesa). En general son ataques de escasa profundidad y referidos a la albura.

\subsection{Problemas derivados del modelo estructural}

La configuración constructiva que se ha descrito en el apdo. 2.1 ha propiciado que en momentos puntuales de gran deformación asociados a cargas importantes -por ejemplo, durante la celebración de los festejos taurinos estivales- las ménsulas desciendan arrastrando verticalmente a los pórticos frontales, que pueden actuar de transición entre dos o más niveles superpuestos repartiendo la solicitación hasta encontrar el equilibrio con la capacidad de respuesta. Este efecto produce dislocaciones y problemas locales que no pueden recuperarse al cesar la carga, permaneciendo las piezas fuera de su posición original. Por ello pueden observarse no pocos casos en los que los extremos de las viguetas no llegan a apoyar en la presunta viga que en principio debería servirles de sustento (Fig. 8). Esta falsa apariencia porticada ha propiciado que en algunos casos se hayan introducido cuñas u otros elementos para calzar la distancia entre viguetas y viga (Fig. 21). Tan prudente como desorientada actuación puede resultar perjudicial, y agravar la situación en el siguiente ciclo de carga.

Uno de los objetivos del análisis estructural será verificar si, en su configuración actual, la estructura de cada nivel es autosuficiente pero, además, teniendo en cuenta el modelo estructural descrito se podrá actuar cons-
21. Cuñas y otros objetos calzando las viguetas.

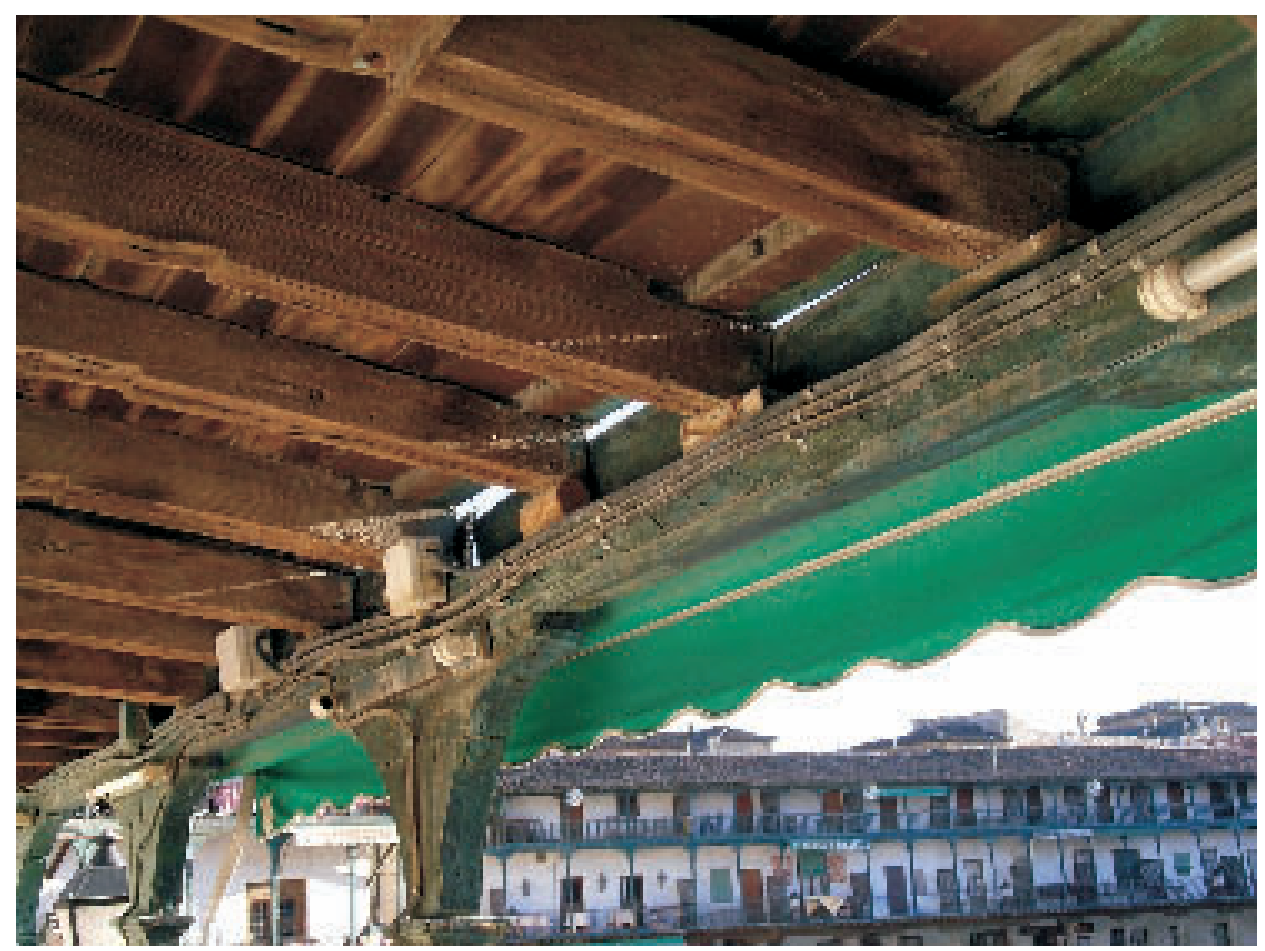


22. Empalme defectuoso en zapata.

23. Empalme defectuoso en viga.

24. Elementos emergentes perjudiciales.
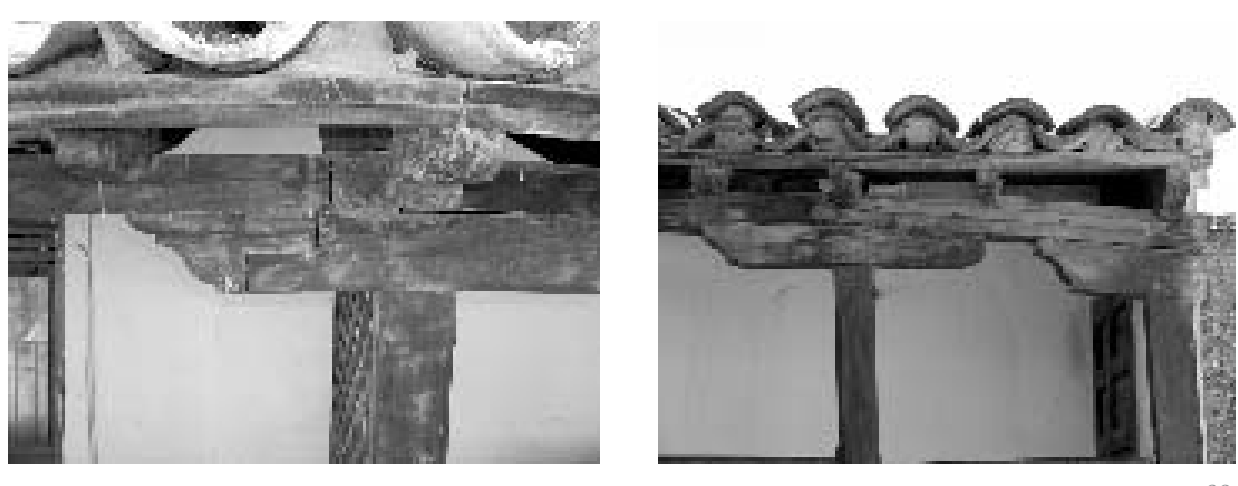

22

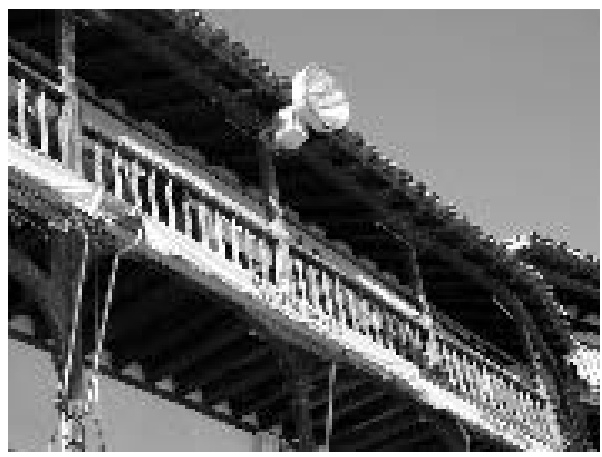

tructivamente de forma más orientada, por ejemplo independizando la conexión estructural entre niveles sucesivos y permitiendo la deformación estructural recuperable, sin repercusiones negativas en otros elementos constructivos.

\subsection{Otras lesiones constructivas}

La enorme cantidad y variedad de defectos constructivos detectados, cuyo tratamiento pormenorizado desbordaría los límites de este artículo, puso a prueba la codificación y metodología desarrollada (14), que hubo de completarse y perfeccionarse en determinados aspectos.

Destacaba en este apartado la detección de diversas intervenciones no afortunadas que deberán corregirse (Figs.22 y 23).

Además, muchos de los daños derivados de la acción del agua responden no al hecho de estar la estructura a la intemperie, como siempre estuvo desde su construcción, sino a la implantación mucho más reciente de todo un repertorio de elementos emergentes como faroles, focos, toldos, etc. (Fig. 24) que producen un efecto de salpicadura y escorrentía que está resultando claramente dañina para muchos de los elementos lígneos. Algunos de ellos, además, se encuentran colocados sin ningún criterio, y el daño potencial se incrementa por su peso individual y el hecho de estar en voladizo.

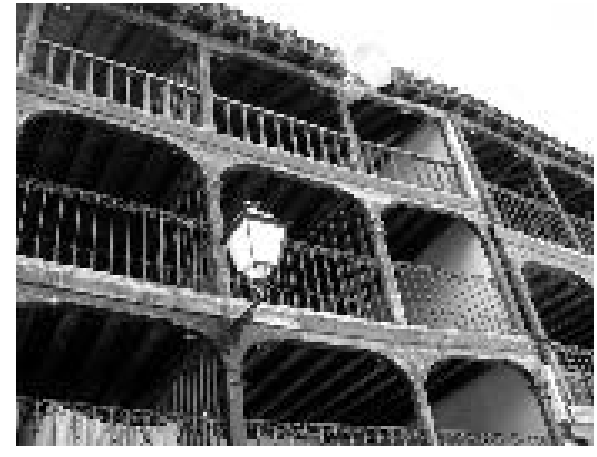

24

En el estudio histórico realizado se ha localizado una referencia a una posible reducción de los aleros en una intervención realizada a finales de los años '60. Además y drenaje del agua pluvial, que cae libremente desde los tejados $y$, ayudada por el viento, moja regularmente la estructura de madera con efectos gravemente perjudiciales. Por un lado perjudica sus prestaciones al aumentar su grado de humedad, lo cual conlleva agotamientos locales en las piezas más cargadas -por ejemplo aplastamientos en algunas zonas de durmientes bajo los pies derechos (Figs. 25 y 26)- o deformaciones inadmisibles en viguetas a flexión. Por otro lado, el mayor grado de humedad incrementa muy significativamente el riesgo de ataques por organismos xilófagos, especialmente hongos de pudrición, provocando desencajes y otros problemas graves (Figs. 27 y 28).

\subsection{Peritación estructural}

Una vez realizada la identificación de especie, clasificación visual y asignación de clase resistente, sobre los elementos seleccionados se ha efectuado un análisis estructural de acuerdo a los criterios y bases de cálculo establecidos en el Eurocódigo 5 (1), pues en la fecha de realización de este trabajo no se había publicado el Código Técnico de la Edificación DB SE-M. La peritación estructural se ha efectuado sobre un estos no cuentan con sistema de recogida 

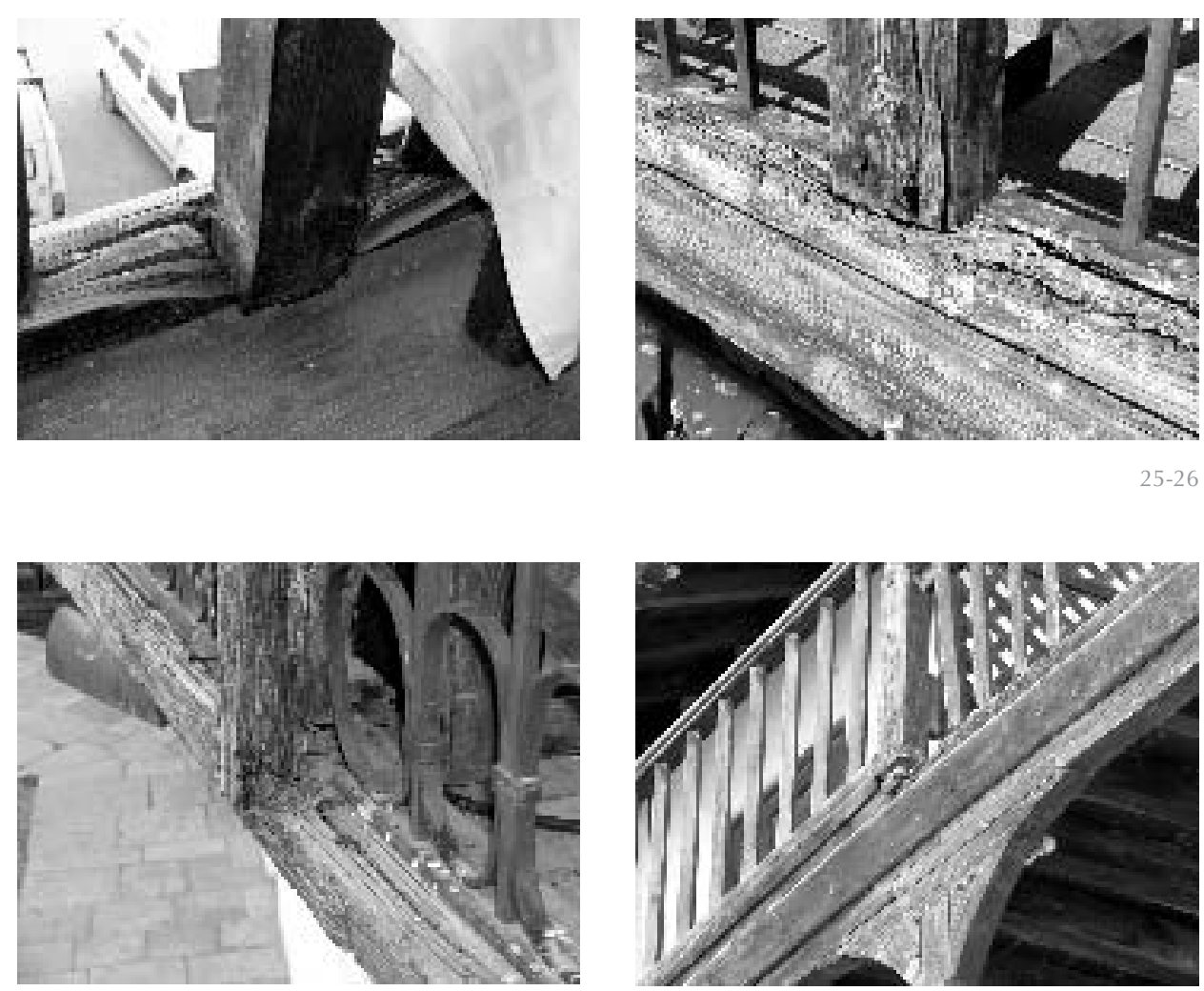

$27-28$

muestreo, eligiendo una pieza representativa del tramo en su situación más desfavorable. Por lo tanto, a tal esquema pueden no responder individualmente todas las integrantes del mismo que, en general, estarán en situación más segura. Se han calculado un total de ocho piezas de la Unidad 1 y 25 del resto de unidades, una por cada tipo distinto. Los cálculos presumen que las piezas están en buen estado y exentas de patologías. Se producen cuatro situaciones:

- Elementos que resultaban válidos en su configuración actual: piezas que han reflejado un índice de agotamiento menor que la unidad en Estados Límites Últimos y deformaciones aceptables, de acuerdo a los tres criterios establecidos por el Eurocódigo 5.

- Elementos cuya configuración constructiva debía revisarse para responder al modelo teórico: barras que no pueden entrar en el grupo anterior en su estado actual, pero sí lo harían con algunos cambios en la configuración constructiva. Por ejemplo: protecciones adecuadas de la lluvia que las permiten pasar de clase de servicio 3 a 2, o limitaciones en la sobrecarga, por ejemplo mediante ocupaciones permanentes con elementos ligeros y compatibles con la estética del edificio.

- Elementos a reforzar y/o consolidar: piezas que no cumplen las condiciones de agotamiento y deformación en su estado actual, ni pueden llegar a hacerlo con operaciones de reparación y declasado como las del

apartado anterior. En estos casos se hace imprescindible la intervención en términos de consolidación y refuerzo que tienen como finalidad mejorar las propiedades mecánicas o de servicio de los elementos en madera con modificaciones mínimas.

- Elementos a sustituir y/o reforzar mediante prótesis: piezas rotas o con daños importantes que hacen inviable su conservación y/o consolidación. Específicamente se desaconsejan, con carácter general, las prótesis realizadas con resinas epoxi y varillaje de fibra de vidrio, por el diferente comportamiento a medio y largo plazo de los añadidos y el material leñoso. A los efectos de prescribir, vía Pliego de Condiciones Particulares del proyecto, madera nueva de aportación, se incluyeron las características esenciales del material original.

\section{CONCLUSIONES Y PROPUESTA DE INTERVENCIÓN}

Respecto de la metodología empleada, se ha demostrado la utilidad de un procedimiento original de inspección, diagnóstico, representación y peritación estructural de estructuras de madera orientado al proyecto, puesto a punto en los últimos años por los autores de este trabajo (6)(13).

Se ha basado en una colección limitada de técnicas visuales e instrumentales de carácter no destructivo, portátiles y con posibilidad de uso en obra.
25-26. Aplastamiento por pudrición.

27-28. Desencaje por pudrición. 
Cada una de las técnicas empleadas ha aportado información relevante, según se ha detallado en apartados anteriores, y ha justificado su rendimiento en obra. Se ha demostrado la utilidad de combinar varias técnicas no destructivas, llegando a su integración final en un documento hipertextual, en formato PDF, que si bien no tiene las prestaciones de navegación que otros formatos alternativos, como el html, permitió la integración de toda la información y la posibilidad de navegación a su través en la versión digital, a la vez que admitía la impresión directa en formato papel. Esto permite analizar fácilmente los resultados por técnicos ajenos al proceso de diagnóstico, facilitando el acierto en la toma de decisiones de intervención.

La integración de los resultados obtenidos mediante la campaña de ensayos no destructivos ha permitido determinar las características mecánicas generales de la madera de la estructura, según se refleja en la Tabla 5. Esta clasificación mixta, a caballo entre más de una clase resistente, resulta ser la más adecuada para clasificar este tipo de piezas de madera de escuadrías medianas y grandes.

En cuanto a la intervención propuesta, y de acuerdo a los principios generales que deben regir la conservación de las estructuras históricas en madera ratificados por la $12^{\text {a }}$ Asamblea General del ICOMOS (12), el objetivo prioritario debería ser el mantenimiento de la autenticidad histórica y la integridad del conjunto arquitectónico, conservando al máximo la estructura histórica y la función que le es inherente, así como revelar su valor cultural mejorando la percepción de su integridad histórica, de sus estadios anteriores y de su concepción original. Por consiguiente se deben conservar al máximo los materiales existentes, e intervenir lo menos posible en el entramado estructural histórico sería lo ideal. En algunos casos, la intervención mínima dirigida a asegurar la preservación y conservación de estas estructuras de madera podrá incluir su desmontaje, total o parcial, y su montaje subsiguiente, a fin de permitir que se efectúen las reparaciones necesarias. Así pues, la intervención deberá tender a:

- Utilizar métodos y técnicas tradicionales.

- En la medida de lo posible, ser técnicamente reversible.
- Al menos, no estorbar o impedir los trabajos de conservación, que pudieran ser ulteriormente necesarios.

- No impedir el acceso, en el futuro, a las informaciones incorporadas en la estructura.

Las piezas y otros elementos retirados deben ser catalogados y sus muestras características deben ser guardadas de manera permanente como parte de la documentación. Los casos de sustitución se deberán limitar al máximo, reflejar documentalmente y marcar discretamente a cuchillo o mediante pirograbado.

Es de crucial importancia mantener una estrategia coherente de vigilancia continua y de mantenimiento regular en el medio y largo plazo.

\subsection{Intervenciones constructivas y de rehabilitación}

Por las razones apuntadas especialmente en el apdo. 4.9, se recomendó considerar la posibilidad de implementar canalones de recogida de agua de los tejados en el frente de los aleros, de material y coloración adecuados. Además, e indefectiblemente en caso de no colocarse estos, será necesaria la retirada de los aparatos de iluminación y proyectores recolocándolos en posiciones distintas, por ejemplo anclados en los muros, sin que su sujeción dependa de las piezas de madera. Esto último sería extensible a los toldos y marquesinas, especialmente la del nivel de planta baja en las unidades 1 y 2.

En cuanto a la meteorización de los frentes de muchas de las viguetas en voladizo, puede incorporarse una tapeta de protección de la misma madera, tratada en profundidad contra la intemperie, que sirva de protección a la pieza original pero que pueda reponerse, actuando a modo de fusible para la mejor preservación a largo plazo de la madera original. En la misma línea, propusimos contemplar la posibilidad de incorporar protecciones sobre la parte superior de los durmientes, de manera que no se encuentren tan expuestos al agua de la lluvia y las salpicaduras como en la configuración actual. Una chapa de cobre oxidado, con una pequeña vuelta y goterón en su borde exterior, podría cumplir satis-

Tabla V

Propuesta de clasificación

\begin{tabular}{|c|c|c|}
\hline $\begin{array}{c}\text { ESTADOS LÍMITE ÚL- } \\
\text { TIMOS }\end{array}$ & $\begin{array}{c}\text { ESTADOS LÍMITE DE } \\
\text { SERVICIO }\end{array}$ & DENSIDAD MEDIA \\
\hline $\mathbf{C 1 6}$ & $\mathbf{C 2 2}$ & $\mathbf{5 5 0} \mathbf{~ k g} / \mathrm{m}^{3}$ \\
\hline
\end{tabular}


factoriamente esta misión. Igualmente, las bases de los pilares podrían incorporar un babero de protección que no permita que el agua que cae y resbala sobre la parte superior del durmiente degrade las bases de los pies derechos de la forma generalizada que se aprecia actualmente.

Otro problema general serían los desencajes de nudos y encuentros, debidos, en la mayor parte de los casos, a movimientos asociados a sobrecargas importantes que hacen deformarse a la estructura sin que esta pueda retomar la posición original de todas las piezas. Por ello es importante considerar el verdadero trabajo estructural de las diferentes barras, tal como se ha descrito en los apartados correspondientes, de manera que las intervenciones que se acometan en el futuro sean compatibles con su necesaria deformación al entrar en carga. En este sentido sería necesario garantizar la estabilidad y resistencia del entramado superpuesto frente a acciones horizontales (empuje de los espectadores) incluyendo juntas de deformación en el sentido vertical, que permitan un cierto movimiento de las barras principales, sin perjudicar a los encuentros. Este problema se detecta especialmente en las vigas frontales del nivel de cubierta, que se encuentran en muchos casos giradas hacia fuera.

Por último, a nuestro juicio se debería retomar la reflexión acerca de la propuesta, fallida en la última intervención de 1992, sobre el color añil original. A pesar de las reticencias entonces observadas, la documentación histórica apunta a que el color verde actual tiene una antigüedad de apenas medio siglo, cuando la historia de la plaza alcanza mucho más. El color azulado indicado es tradicional en toda la zona geográfica y se debe a un producto natural de origen vernáculo que protagonizó el aspecto característico e histórico de la plaza hasta hace bien pocos años.

\subsection{Tratamiento curativo y preventivo}

El estado general de la madera es relativamente bueno gracias a actuaciones realizadas anteriormente, de 1966 a 1969, saneado de todas las galerías, reposición de piezas, etc. y las últimas realizadas en el proyecto de restauración y consolidación de fachadas inaugurado en 1992. Sobre la madera que no presenta síntomas de ataques ni abiótico ni bióticos se aconsejó un tratamiento preventivo superficial de forma que la penetración media alcanzada por el protector sea de $3 \mathrm{~mm}$, siendo como mínimo de $1 \mathrm{~mm}$ en cualquier parte de la superficie tratada. Se corresponde con la clase de penetración P2 de la norma UNE-EN 351-1:1995.

En las zonas con meteorización se aconsejaron saneados superficiales, eventualmente con tratamientos superficiales contra la fotodegradación y pasar al caso anterior. Para el caso de las maderas atacadas por insectos xilófagos y hongos de pudrición se prescribieron tratamientos convencionales de curación mediante inyecciones y válvulas unidireccionales para impregnación de profundidad media, con saneados mecánicos en las zonas más afectadas.

Para la madera de aportación se recomendó un tratamiento de profundidad media, de forma que la penetración media alcanzada por el protector sea al menos de $6 \mathrm{~mm}$ en las caras laterales de la albura. Se corresponde con las clases de penetración P4-P6 de la norma UNE-EN 351-1:1995. Al tratarse de elementos de nueva aportación este tratamiento puede ser aplicado en autoclave o por inmersión.

\section{AGRADECIMIENTOS}

Este trabajo ha sido financiado por la Dirección General de Patrimonio de la Comunidad de Madrid y por el Ministerio de Fomento, en el marco de las Acciones Estratégicas sobre "Mantenimiento y evaluación de estado de obras y edificios" del Área Sectorial "Construcción Civil y Conservación del Patrimonio Histórico Cultural" del Plan Nacional de Investigación Científica, Desarrollo e Innovación Tecnológica 2000-2003". Ha contado con la colaboración de la empresa privada Técnicas para la Restauración y Construcciones S.A., TRYCSA.

\section{BIBLIOGRAFÍA}

(1) UNE-EN 1995-1-1 Eurocódigo 5. Proyecto de estructuras de madera. Parte 1-1: Reglas generales y reglas para edificación.

(2) Acuña, L.; Díez Barra, R.; Basterra, L.A.; et al. "La técnica de transmisión ultrasónica aplicada a la madera estructural". 11 ${ }^{\circ}$ Congreso Español de END. Sociedad Española de Ensayos no Destructivos AEND. Gijón (España), 2007. pp. 91-102.

(3) Acuña, L.; Barranco, I; Casado, M.; et al. "Análisis y validación de la técnica resistográfica aplicada a la madera estructural". $11^{\circ}$ Congreso Español de END. Sociedad Española de Ensayos no Destructivos AEND. Gijón (España), 2007. pp. 343-354.

(4) Arriaga, F., Peraza, F., Esteban, M., Bobadilla, I., García, F. Intervención en estructuras de madera. AITIM, Madrid, 2002. 
(5) Arriaga Martitegui, F., Íñiguez González, G., Esteban Herrero, M., \& Bobadilla Maldonado, I. Madera aserrada de gran escuadría para uso estructural y sus particularidades. Informes de la Construcción. Vol. 59, №. 506 (2007), pp. 29-41. doi:10.3989/ic.2007.v59.i506.505.

(6) Basterra, L.A.; Casado, M.; Acuña L.; Ramón-Cueto, G.; López, G.; Barranco, I.; Relea, E. "Avance de propuestas metodológicas para el diagnóstico y análisis de estructuras de maderas históricas". Actas del Cuarto Congreso Nacional de Historia de la Construcción: Cádiz, 27-29 de enero de 2005 / coord. por Santiago Huerta Fernández, Vol. 1, pp. 121-132.

(7) Basterra, L.A.; Casado, M.; Acuña L.; Pinazo, O. "Técnicas de ensayo pseudo no destructivas en madera estructural mediante extracción de tornillos". Revista electrónica ReCoPaR, N. 2 (2006), pp. 37-59. ISSN 1886-2497.

(8) Bucur, V. Nondestructive characterization and imaging of wood. Springer Berlin, 2003.

(9) Conde García, M., Fernández-Golfín Seco, J., \& Hermoso Prieto, E. "Mejora de la predicción de la resistencia y rigidez de la madera estructural con el método de ultrasonidos combinado con parámetros de clasificación visual". Mater. Construcc., Vol. 57, № 288 (2007): pp. 49-59. doi:10.3989/ mc.2007.v57.i288.64.

(10) Esteban Herrero, M. Determinación de la capacidad resistente de la madera estructural de gran escuadría y su aplicación en estructuras existentes de madera de conífera. Tesis Doctoral, E.T.S.I. Montes (UPM), 2003. oai:oa.upm.es:1404.

(11) Hermoso Prieto, Eva. Caracterización mecánica de la madera estructural de Pinus sylvestris L. Tesis doctoral, E.T.S.I. Montes (UPM), 2001. oai:oa.upm.es:644.

(12) ICOMOS: "Principios que deben regir la conservación de estructuras de madera". Ratificados en la $12^{\mathrm{a}}$ Asamblea General en México, 1999.

(13) Ramón-Cueto, G. Propuesta de metodología orientada al proyecto para la evaluación de los elementos estructurales de madera en el patrimonio histórico español. Tesis doctoral, Universidad de Valladolid, 2007.

(14) Ramón-Cueto, G., Basterra, L.A., Acuña, L., Casado, M., López, G. "Codificación y representación de resultados en las inspecciones de estructuras de madera del patrimonio histórico orientadas a la elaboración del proyecto de restauración arquitectónico". Ilas Jornadas de Investigación en Construcción. Inst. Ciencias de la Constrcc. Eduardo Torroja. Madrid, 2008.

(15) Rinn, F. "Metodología de Inspección en Construcciones de Madera", Revista CIS-Madeira, n 12, $1^{\text {er }}$ semestre, 2004. pp. 19-31. 